\title{
METAMORFOSES DA FENOMENOLOGIA
}

\section{Maria José Cantista}

Faculdade de Letras da Universidade do Porto

Um século volvido sobre os primeiros escritos de Husserl, estamos em condição de apreciar o peso específico da fenomenologia como corrente de pensamento marcante da contemporaneidade.

Face à crise de fundamentos da metafísica moderna, a fenomenologia apresenta-se como alternativa, quer ao descrédito do método por demonstração causal, quer à pura e simples dispensa de método pela mostração infundamentada da experiência empírica. Como dizia Landsberg, a fenomenologia, na tentativa de reposição do fundamento radical, tentou destruir o "famoso dilema entre um empirismo mutilado por uma hipótese sensualista, e um racionalismo reduzido ao pensamento carente de intuição"1.

A fenomenologia husserliana veio potenciar uma nova noção de racionalidade, unindo o extremo subjectivismo (de pendor idealista-formalista) e o extremo objectivismo (naturalista-materialista) ${ }^{2}$. É da noção de fenómeno, tomado na acepção de experiência originária do sentido, que radicará a fenomenologia como metamorfoseamento de si. Longe de remeter a fundamentação da racionalidade para um Logos préexistente, ela discursa-se como a arte da realização da racionalidade, num percurso incoativo, em radicalização de $\mathrm{si}^{3}$. Captar o sentido do mundo e das coisas, no seu estado nascente, eis um esforço ou uma exigência sem fim pré-assinalado.

As noções cruciais da fenomenologia de Husserl (intencionalidade, noese,

\footnotetext{
${ }^{1}$ P. Landsberg, «Husserl et l'idée de la philosophie», in Rev. Int. Phil. 1939, p. 321.

${ }^{2}$ Cf. M. Merleau-Ponty, Phénoménologie de la Perception, Gallimard, Paris, 1945, p. XV.
} 
noema, redução, fenómeno, etc) serão incessantemente reapreciadas, no intuito de uma depuração crescente do sentido do fenómeno puro, da significação da coisa, tal como se dá à consciência intuitiva.

Assim sendo, fenomenologia em metamorfose de si ou método redutivo, bem poderiam considerar-se como expressões equivalentes. E é justamente daqui que radicarão as minhas considerações: tentarei focalizar como, já em Husserl, a fenomenologia opera sucessivas reduções (qual tarefa interminável, no dizer de E. Fink e de M. Ponty), sendo, por isso mesmo, uma metamorfose de si; esta prossegue nos seus discípulos, apresentando a noção de fenómeno, sentidos diferenciados no âmbito de uma racionalidade mais ampla e complexa - mais rica - e cada vez mais distanciada da racionalidade moderna a que o primeiro Husserl estava, ainda assim, atado.

A ambivalência da noção de fenomenologia, longe de nos colocar face a uma imprecisão deficitária de sentido, proporciona-nos uma riqueza hermenêutica intimamente relacionada com a busca de fundamentação radical.

$\mathrm{Na}$ verdade, quanto mais rica é uma corrente ou um pensador, tanto mais rica e criativa é a interpretação que proporciona, por vezes até mesmo em versões antitéticas, e num mesmo espírito de fidelidade à mensagem que Ihe é inerente.

A filosofia de Hegel, por exemplo, foi considerada por uns como a Teologia, e por outros como a primeira manifestação do ateísmo filosófico contemporâneo. Hegel, ao pensar absolutamente o Absoluto, tê-lo-ia dispensado.

Regressemos, pois, à nossa questão: qual o sentido do fenómeno como fundamento, em Husserl?

Ele apresenta, logo à partida, um duplo sentido, como no-lo recorda o filósofo na sua obra A ideia da fenomenologia. É simultaneamente o objecto que se dá, e a sua constituição por e a partir do sujeito. ${ }^{4}$

\footnotetext{
${ }^{3}$ Cf. op. cit., pp. XV-XVI

${ }^{4}$ E. Husserl, A ideia da fenomenologia. Hua II, 14, 11-14; tr. Fr. P. 116, cit. in J. L. Marion, Étant donné, P.U.F., Paris, 1998. Já na obra A ideia da fenomenologia, Husserl chama a atenção para o facto da palavra fenómeno admitir um duplo sentido (doppelsinig), em virtude da correlação essencial entre o aparecer (Erscheinen) e o aparecente (Erscheinenden).
} 
No que comummente designamos por primeiro Husserl, o fenómeno destaca-se como pura evidência, no âmbito das idealidades lógico-matemáticas, inerente a uma racionalidade de pendor lógico-abstractiva. Trata-se de um fenómeno que goza de universalidade, de perenidade, de homogeneidade, de previsibilidade, no mundo das idealidades, cuja simplicidade permite uma captação por intuição apodíctica.

Nos últimos escritos de Husserl, parafraseando Eugen Fink, late uma tensão entre o regresso ao mundo vivido por uma interrogação históricogenética e o ideal de uma ciência universal, fundada na natureza eterna de um homem que se reconhece e compreende como animal racional ${ }^{5}$.

A verdadeira significação do regresso às coisas mesmas (Leibhaft) será então o restabelecimento da imediatez com os sendos, na busca de um conhecimento mais originário (verusprüng lichung alles wissens) que não é já pura teoria, mas movimento vital do homem (eine Lebensbewegung des Menschen).

O fenómeno passa a ser preferentemente focalizado com a Lebenswelt que não constituo, por estar sempre e já nela instituído. A originareidade fenoménica passa agora para a preconstituição de um sujeito afectado; e a preobjectividade, não sinónima de irracionalidade, exibe o surgimento do sentido começante. A redução conduz o Eu penso (Ich denke) ao Eu posso (Ich kann) de donde radica; e a intencionalidade constituinte, ao nível da consciência de posição, sabe-se precedida e dependente de uma intencionalidade de situação, operante (fungierende Intentionalitat).

A par das significações conhecidas, irrompem as significações vividas aquelas, em irremediável atraso relativamente a estas. Merleau-Ponty, com base nos manuscritos de Husserl, designará a Verdade como "movimento retrógrado", na tentativa de "igualar a reflexão à vida irreflectida da consciência".

O fenómeno radical aparece-nos agora como o fenómeno enraizado na existência, ou, se se quiser, a existência mesma, que precede e excede a mera frontalidade objectual. O fenómeno como ser-objecto será secundarizado, dependente de uma realidade inaugural mais profunda, cujo

\footnotetext{
${ }^{5}$ Cf. «Das problem der Phänomenologie Edmund Husserls» in Rev. Int. Phil, 1, 1939, p. 225
} 
sentido se tratará de detectar.

À medida que a fenomenologia husserliana ganha corpo, têm um papel preponderante os temas da temporalidade, da história, da intersubjectividade, da corporeidade, das emoções, da vontade.

É do "último Husserl" que radicam os seus discípulos mais directos e a atenção prevalente, quer por parte desses seus discípulos mais marcantes, quer dos intérpretes hodiernos, incide na Krisis, Ideen I, I deenI, Erfahrung und Urteil, Ursprung der Geometrie, Urmsturz Kopernikanischen Lehre, Die Phanomenologie der Intersubjecktivität.

Na senda desta metamorfose do fenómeno, Heidegger é um marco referencial. As exigências redutivas levá-lo-ão à proposta do fenómeno como Es gibt, que os franceses traduzem normalmente por il-y-a, ou seja, algo existe, há algo, e que Jean-Luc Marion, no âmbito de uma fenomenologia da doação, traduz por cela donne, isso dá, diríamos nós. Com efeito, para Heidegger, a descrição intencional só será rigorosamente intencional, se tiver por tema a intencionalidade operante, e se for, em si mesma, uma "maneira de operar". O Autor de Ser e Tempo lembra que Husserl se encontrou com o grave problema de que a vida de "formação" e "prestação" do sentido não parece oferecer-se como "objecto" na análise intencional, no mesmo sentido em que se oferecem as coisas e os objectos em geral. Poderemos determinar conceptualmente aquilo por meio do qual obtemos coisas, objectos? Está em jogo o ser da intencionalidade e este será em definitivo o "fenómeno originário"6.

O ser da intencionalidade não será mais da ordem do ser-posto, pelo que o Dasein, como in-der- Welt-Sein é agora o fenómeno radical.

Em Merleau-Ponty, tal originareidade, o que designa por fenómeno do fenómeno, será a percepção.

Não é meu objectivo, na presente comunicação, deter-me numa analítica deste metamorfoseamento, descendo, por exemplo, ao pormenor comparativo das noções-chave da fenomenologia, quer em Husserl, quer nos fenomenólogos pós-husserlianos, designadamente Heidegger e M. Ponty.

${ }^{6}$ Cf. op. cit., p. 270 
Com efeito, o sujeito, a intencionalidade, a noese, o noema, a reflexão, sofrem transformações, por exigências de radicalização do sentido que lhes é inerente.

Merleau-Ponty é um marco importante deste movimento perfomativo: não só pelo pioneirismo no acesso aos manuscritos de Husserl, mas também pela influência que exerceu posteriormente em Lévinas, Ricoeur, Richir, Blanchot, para mais não citar. Poderemos detectar algumas características comuns a este movimento metamorfoseador?

Creio que sim: à medida em que o sentido do fenómeno se vai progressivamente reduzindo, maior é o afastamento do fenómeno como pura evidência racional, e maior é o protagonismo da subjectividade como corporeidade, como carne (auto-afecção). Também o outro, o horizonte, a temporalidade, a historicidade, a síntese passiva e a síntese alógica, a poietização e a praxidade da razão ganham um crescente protagonismo.

O giro a que progressivamente se vai assistindo no que concerne à "localização" do sentido do fenómeno, como adiante se verá, será mesmo de $180^{\circ}$.

Para Marc Richir, foi Heidegger quem inequivocamente encetou tal giro com a "defenestração do sujeito" e foi M. Ponty quem o radicalizou com a fenomenalização do homem a partir de nada, isto é, a partir do que M. Ponty designa por Ser Bruto ou Selvagem ${ }^{7}$.

Lévinas, ao depor o sujeito, propõe uma contra-intencionalidade originária como Desejo. Eu sou sempre e já abertura ao apelo do outro, ao seu mandato ético que me interpela sob a forma de um mandato ao qual respondo. A fenomenalidade originária prende-se, pois, com a responsabilidade originária.

Por exigência de tempo, irei, a partir de agora, deter-me no pensamento de Jean-Luc Marion para ver até que ponto a radicalização da exigência redutiva o conduz à noção de fenómeno na doação.

Basear-me-ei, sobretudo, nas obras Réduction et donation. Recherches sur Husserl, Heidegger et la phénoménologie (1989), e Étant donné. Essai d'une phénoménologie de la donation (1998).

Radicando do lema husserliano - a mais redução, mais doação - , o Autor

\footnotetext{
${ }^{7}$ M. Richir, «La défenestration» in L'Arc, 46, 1971, p. 36
} 
tecerá uma aturada reflexão em torno da equivalência principial entre fenómeno, doação, mostração, na mais pura intrinsecidade da consciência, liberta de toda a tentação de substantivação metafísica: quer do sujeito, quer do acto mesmo da doação.

Marion propõe o que designa por uma terceira redução, depois da de Husserl (fenómeno como evidência objectual) e da de Heidegger (fenómeno como sendo, étant). A redução conduz assim ao fenómeno como doação pura, liberta dos constrangimentos da objectualidade heideggeriana. Na doação, qual explosão incontida de sentido, está ausente todo o tipo de remetência à transcendência: seja por parte do que se dá (le donné, que se encontra do lado do noema), seja por parte do a quem a se dá (l'adonné, que está do lado da noese), seja por parte do acto mesmo da doação que unifica o doador e o donatário. O fenómeno entendido como pura doação reduz a relação entendida como troca-comércio (Derrida) entre doador e donatário.

Não posso, neste momento, deter-me nas razões apontadas pelo Autor na defesa da principialidade da doação. Elas estão minuciosamente apresentadas nos dois primeiros livros de Étant donné.

Centrar-me-ei, ainda assim, e por momentos, no que Marion designa por fenómeno saturado de intuição, que coloca nos antípodas do fenómeno faltoso ou pobre de intuição, isto é, o fenómeno como evidência objectual. Este último, como já tivemos ocasião de referir, encerra uma ambiguidade na correlação essencial entre o aparecer e o aparecente. Tal correlação, afirma o filósofo, orquestra-se (em Husserl) segundo vários pares diferentes, mas articulados entre si: intenção/intuição, significação/preenchimento, noese/noema, etc. Em Husserl - comenta -, o fenómeno é o que aparece em correlato com a aparição. E a mais alta fenomenalidade cumpre-se com a perfeita adequação destes dois termos, quando o aparecer subjectivo equivale ao aparecente objectivo. Tal adequação, segundo Marion, é o vestígio do fenomenismo kantiano, onde a mise en scène intuitiva condiciona a objectivação conceptual.

Platão, Descartes, Kant, Husserl, de acordo com as especificidades das respectivas teorias do conhecimento, privilegiam os fenómenos lógicos e matemáticos, erigidos em modelo de todos os outros, segundo o critério da 
certeza. Caracterizam-se pela sua penúria em intuição e pela sua pobreza em donação. São dados nos limites da finitude do sujeito que os constitui. A irrealidade destes objectos caracteriza-se pela sua riqueza em abstracção e generalidade, e pela sua penúria em individuação, em unicidade, surpresa, imprevisão, maravilhamento, consternação, insuportabilidade.

Regular toda a fenomenalidade sobre o caso essencialmente marginal dos fenómenos pobres em intuição, interdita, segundo Marion, o acesso aos fenómenos de "direito comum", os entes da natureza, o vivente em geral, o acontecimento histórico, o outro, etc.

Dar a vida, a morte, o tempo, são fenómenos excessivos, por relação ao mencionado.

Para Marion, foi Kant quem pressentiu o que designa por fenómeno saturado $^{8}$. No caso da ideia estética kantiana a "representação da imaginação dámuito a pensar sem que, no entanto, um qualquer pensamento determinado ou um conceito possa ser-lhe adequado" ${ }^{\prime \prime}$. Há aqui um excesso de doação que nenhum conceito pode expor. Trata-se de uma sobreabundância intuitiva, não exponível segundo as regras a priori. A intenção não se expõe mais no conceito, satura-o e torna-o sobreexposto, invisível, ilisível, não por defeito, mas por excesso de luz. A ideia estética não organiza a sua intuição nos limites de um conceito, não dá a ver um objecto definido. Tal peculiaridade não a desqualifica. Ela dá-se num livre jogo, o jogo do sublime. Se seguirmos a doabilidade em todo o seu alcance, abandonamos o limite do fenómeno pobre em intuição ou definido pela adequação ideal de intuição e intenção. Nos fenómenos saturados, o que se mostra, dá-se antes de se objectivar. Aliás, eles nunca se objectivariam, se primeiramente se não dessem, nem que fosse sob um modo elementar e humilhado. Em fenomenologia, a menor possibilidade obriga, pelo que o leque da doação é infinitamente aberto, permanecerá sempre em aberto.

Para caracterizar os fenómenos saturados, o filósofo serve-se das categorias kantianas do entendimento que variam segundo a quantidade, a qualidade, a relação e a modalidade. Assim sendo, o fenómeno saturado

\footnotetext{
${ }^{8} \mathrm{~J}$. L. Marion, Étant donné, p. 277

${ }^{9}$ Op. cit., p. 278.
} 
irrompe como invisável (não visável, segundo a quantidade), insuportável (segundo a qualidade), absoluto (segundo a relação) e não olhável (irregardable, segundo a modalidade). As três primeiras categorias de intuição saturada põem em causa a comum acepção de horizonte, a última, a acepção transcendental do eu.

Recorramos, com Marion, a alguma exemplificação. A doação invisável dá-se por síntese instantânea e encontra um exemplo privilegiado no assombro (étonnement). Segundo Descartes, refere Marion, esta paixão afecta-nos, antes mesmo de conhecermos as coisas.

A saturação segundo a qualidade ocasiona uma espécie de cegueira no regime dos fenómenos pobres, ou mesmo comuns. Quando o olhar (regard) não pode suportar o que vê (voit) sofre o deslumbramento (éblouissement). O que pesa nesta intuição não é nada do foro da finitude, mas da glória, do sucesso, da alegria. Este excesso de intensidade de intuição é o que impede o homem, prisioneiro na caverna, de ver a luminosidade das Ideias, ficandose pelas suas sombras. É que, segundo Marion, a finitude experimenta-se, não tanto pela penúria do dado, mas pela impossibilidade de medição da sua (infinita) amplitude, ou, então, no sofrimento de uma passividade essencial. Por outras palavras: a finitude descobre-se melhor, face ao fenómeno saturado, do que face ao fenómeno pobre, isto é, às intuições por evidência lógico-matemática.

A absoluteidade do fenómeno saturado, segundo a relação, exibe uma inediticidade livre de qualquer analogia com outro fenómeno ou horizonte, na sua mais pura incondicionalidade: "vindo para (parmi) os seus, os seus não o reconheceram; vindo na fenomenalidade, o fenómeno absolutamente saturado poderia não encontrar aí qualquer espaço de desdobramento. Esta negação de abertura, esta desfiguração, permanece ainda uma manifestação"10.

O fenómeno saturado segundo a modalidade é o não olhável (irregardable), aquilo que se mostra de si, segundo a sua iniciativa (exigindo anamorfose), o seu ritmo, o seu advento, a sua essencial contingência, qual aparecimento sem reprodução nem repetição. Este fenómeno impõe-se com tal

${ }^{10}$ Op. cit., p. 293 
excesso de intuição que não pode mais reduzir-se às condições de possibilidade da experiência do objectivo, ou seja, a um eu que as fixe. $\mathrm{O}$ eu metamorfoseia-se em testemunho, cuja riqueza de sentido não podemos analisar aqui, porque o tempo escasseia.

Marion cita três exemplos paradigmáticos de fenómenos saturados: a ideia de Infinito em Descartes, a de Sublime em Kant, e a consciência íntima do tempo em Husserl.

Ainda no âmbito da exemplificação, o pensador francês tentará mostrar como o fenómeno histórico satura, subverte a categoria de quantidade (o acontecimento invisável); o ídolo satura a categoria da qualidade; com efeito, a visibilidade de um quadro artístico é sem conceito; rever um quadro não significa adicionar mais uma intuição, mais outra e assim sucessivamente. 0 dado intuitivo do ídolo impõe-nos uma mudança incessante de olhar, nem que seja para nele afrontar o deslumbramento; em lugar de pressupor uma interobjectividade e uma comunicação pelo menos teleológica, como o facto histórico, o ídolo provoca um inevitável solipsismo, individualizando-me radicalmente ${ }^{11}{ }^{11}$ A carne satura, subvertendo a categoria de relação como autoafecção. A propósito, afirma o Autor: "a carne auto-afecta-se na agonia, no sofrimento, na dor, como no desejo de sentir, no orgasmo"12 ${ }^{12} \mathrm{O}$ ícone satura a categoria da modalidade. O ícone é o não olhável. Com efeito, ele não oferece nenhum espectáculo ao olhar.

Concluindo: a definição de fenómeno como dado liberta-o dos limites da objectividade (Husserl) e da estanticidade (étantité, Heidegger); o dado só se mostra a partir de si, na medida em que se dá em e a partir de si, ou seja, deixando o si. A descrição dos fenómenos saturados de intuição alargam infinitamente o campo da fenomenalização.

A máxima radicalização do fenómeno como doação exerce-se na doação do outro como pura individuação. E tal radicalização fenomenológica designa-se por amor ${ }^{13}$. A propósito, afirma o Autor:

\footnotetext{
${ }^{11}$ Op. cit., p. 323

12 Op. cit., p. 322

${ }^{13}$ Op. cit., p. 443
} 
"Receber o outro equivale, antes de mais, a receber um dado e receberse. O próprio adonné (o a quem é dado) releva da fenomenalidade da doação e, portanto, neste sentido, dá-se, também de um modo privilegiado"14. E prossegue: “Quando o outro se mostra, trata-se com efeito de um adonné dando-se a outro adonné"15. Não estamos mais perante a intersubjectividade ou a interobjectividade, mas perante a interdoação.

A obra Étant donné termina assim com a radicalização do sentido do fenómeno como amor. Já Heidegger afirmara "o amor como motivo de fundo da compreensão fenomenológica"16.

Ao fenómeno do amor dedicará posteriormente Marion a obra intitulada Le phénomène érotique.

\footnotetext{
14 Op. cit., p. 442

${ }^{15}$ Op. cit., p. 443

${ }^{16}$ M. Heidegger, Grundprobleme der Phänomenologie, GA 58, p, 185, citado em Étant donné,p. 443
} 